\title{
POLYCYSTIC KIDNEYS IN THE RED PANDA (AILURUS FULGENS)
}

\author{
Modesta Makungu, B.V.M., M.V.M., Wencke M. du Plessis, M. Med. Vet. (Diag. Im.), Dipl. \\ E.C.V.D.I., Michelle Barrows, B.V.M.S., ZooDipl. Med. (Avian), Katja N. Koeppel, B.V.M.S., M.Sc. \\ (Wildlife), and Hermanus B. Groenewald, B.V.Sc., Ph.D.
}

\begin{abstract}
An intact adult male 14.3-yr-old red panda (Ailurus fulgens) presented for health examination with a history of slowly progressing loss of body condition. Abdominal radiographs revealed a truncated abdomen with poor serosal abdominal detail and multiple areas of spondylosis with some collapsed intervertebral disc spaces. On computed tomography, multiple ovoid hypoattenuating lesions were seen in the left and right kidneys. Gross pathology and histopathology revealed multiple cystic lesions in the kidneys concurrent with pancreatic cysts on histopathology. To the best of the authors' knowledge, polycystic kidneys have not been reported in this species.

Key words: Ailurus fulgens, cyst, kidney, pancreas, polycystic kidney disease, red panda.
\end{abstract}

\section{BRIEF COMMUNICATION}

The red panda (Ailurus fulgens) is an arboreal animal primarily distributed in southern China and the Himalayas. ${ }^{6}$ In the wild, its average lifespan is 8 to $10 \mathrm{yr}$, whereas in captivity is $13.4 \mathrm{yr}^{10}$

Polycystic kidney disease (PKD) has been reported in humans ${ }^{7,11,16}$ and in various animal species such as domestic cats ${ }^{1,3,4}$ and dogs..$^{12,14}$ In domestic cats, the disease is more prevalent in Persian cats; ${ }^{4}$ in dogs, it is more prevalent in terrier breeds. ${ }^{12,14}$ The two forms of the disease are autosomal recessive PKD and autosomal dominant PKD and both have been reported in humans, ${ }^{11,16}$ domestic cats, ${ }^{1,3}$ and dogs. ${ }^{12,14}$

This report describes a case of multiple cystic lesions in the kidneys concurrent with pancreatic cysts in an adult red panda resembling those seen in domestic cats and dogs with PKD. To the best of the authors' knowledge it has not yet been reported in this species.

An intact male 14.3-yr-old red panda presented for health examination with a history of slowly progressing loss of body weight. Physical examination revealed a thin body condition score of $1.5 / 5$ (weight $=3.7 \mathrm{~kg}$ ) and all the premolar and molar teeth were worn down to the gum line. Abdominal palpation was normal. Hematology and biochemistry parameters revealed mild ane-

From the Department of Anatomy and Physiology, Faculty of Veterinary Science, University of Pretoria, Private Bag X04, Onderstepoort 0110, South Africa (Makungu, Groenewald); Ross University School of Veterinary Medicine, P.O. Box 334, Basseterre, St. Kitts, West Indies (du Plessis); Bristol Zoo Gardens, Clifton, Bristol BS8 3HA, United Kingdom (Barrows); and Johannesburg Zoo, Private Bag X13, Parkview, Johannesburg 2122, South Africa (Koeppel). Correspondence should be directed to Dr. Makungu (modesta_makungu@ yahoo.com). mia (hematocrit, $32.8 \%$ : reference, $39.3 \pm 0.05 \%$; mean corpuscular volume, $37.6 \mathrm{fl}$ : reference, 46.3 $\pm 5.20 \mathrm{fl}$ ), high levels of alkaline phosphatase (56U/L: reference, $28 \pm 21 \mathrm{U} / \mathrm{L}$ ) and low levels of blood urea nitrogen $(5.3 \mathrm{mM} / \mathrm{L}$ : reference, $9.64 \pm$ $3.21 \mathrm{mM} / \mathrm{L}$ ). No blood parasites were detected.

Abdominal radiographs revealed a truncated abdomen with poor serosal abdominal detail and multiple areas of spondylosis with severely affected areas involving $\mathrm{T} 13$ and $\mathrm{T} 14, \mathrm{~L} 1$ and L2, L3 and L4, with collapsed intervertebral disc spaces.

Computed tomography (CT) revealed multiple ovoid hypoattenuating lesions up to $5 \mathrm{~mm}$ in diameter within the left and right kidneys with the majority of the lesions being located in the cortex (Fig. 1). On postcontrast images, these lesions were accentuated. The right kidney measured 3.79 $\mathrm{cm}$ in length, $1.92 \mathrm{~cm}$ in height, and $2.19 \mathrm{~cm}$ in width, whereas the left kidney measured $3.79 \mathrm{~cm}$ in length, $2.05 \mathrm{~cm}$ in height and $2.02 \mathrm{~cm}$ in width on postcontrast images. A 2.7-mm-diameter round hyperattenuating lesion was seen in the right cranial liver.

Due to health deterioration, the animal was euthanized. Gross pathology revealed multiple variable-sized cystic lesions in the left and right kidneys (Fig. 2). Histopathology revealed mild to moderate dilatation of renal tubules, some with a cystic appearance. Some renal tubules contained protein casts with attenuation of tubular epithelial cells and a few had epithelial cell degeneration. Multifocal areas of mild interstitial fibroplasia were also evident. Cystic dilatation of the pancreatic ducts was also visualized. Accumulation of hemosiderin in the cytoplasm of Kupffer cells and multifocal bile stasis in the canaliculi was also observed. A focal portal tract showed bile duct hyperplasia with mild lymphoplasmacytic infiltration. Diagnosis of polycystic kidneys was made based on CT, gross pathology, and histopathology 

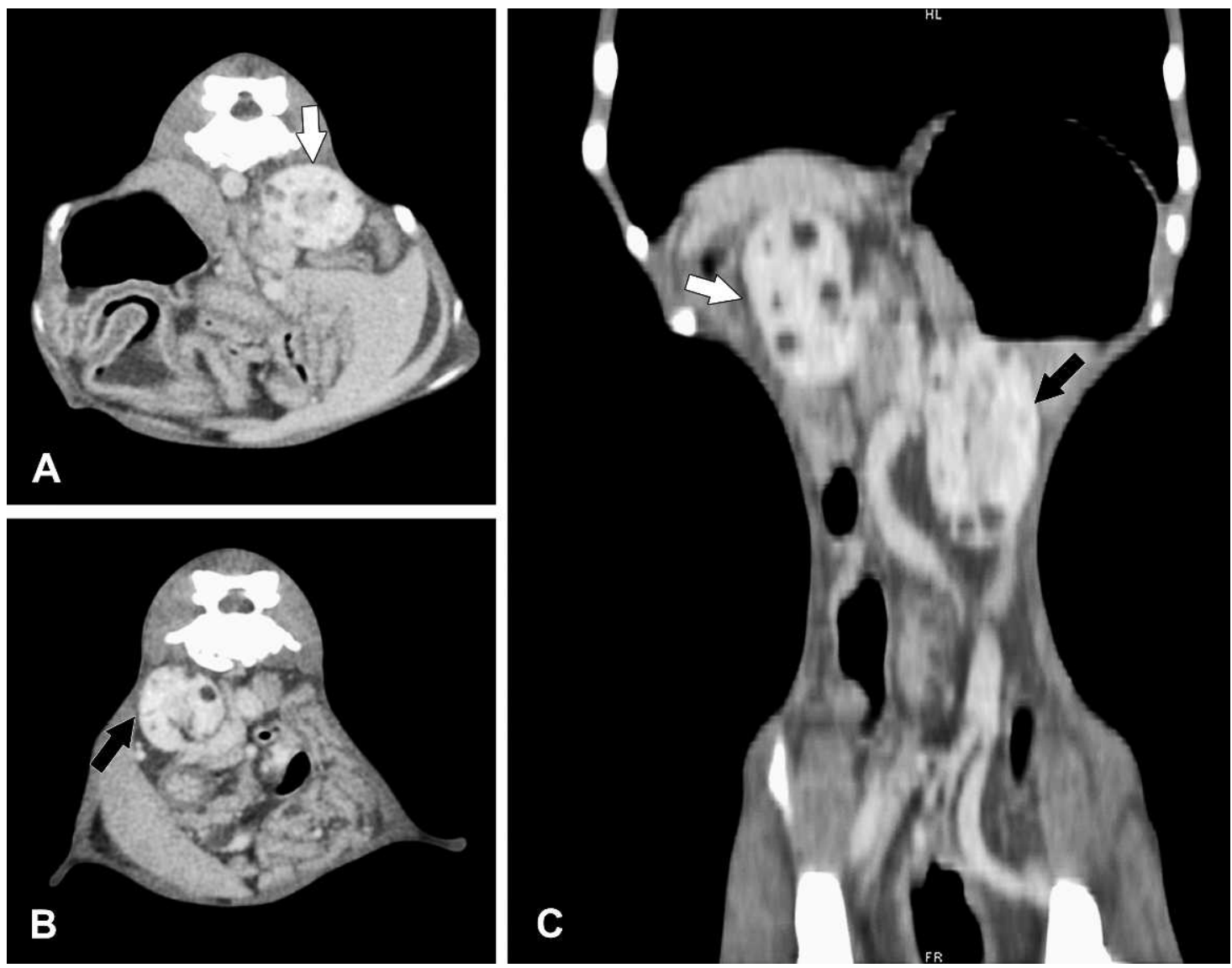

B

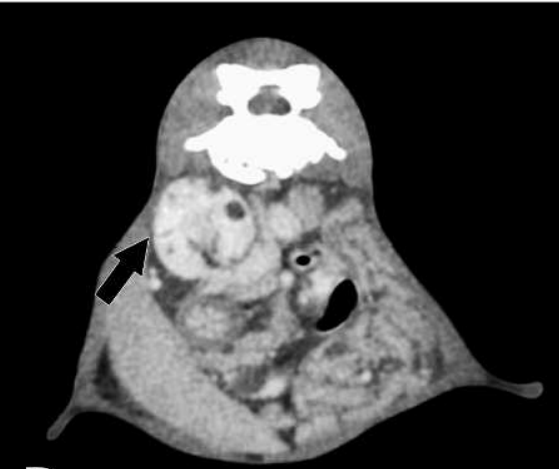

Figure 1. (A and B) Transverse and (C) dorsal abdominal postcontrast computed tomographic images using a soft tissue window (window width $[\mathrm{WW}]=400$, window level $[\mathrm{WL}]=40$ ). Images are $(\mathrm{A})$ at the level of the right kidney and (B) at the level of the left kidney. Note the presence of multiple ovoid hypoattenuating lesions variable in size involving the left (black arrow) and right (white arrow) kidneys with the cortices being severely affected. Note also $(\mathbf{C})$ the truncated abdomen.

concurrent with pancreatic cysts on histopathology.

Renal cysts may be inherited or acquired. Inherited renal cysts have been observed in domestic cats ${ }^{1,3}$ and dogs ${ }^{12,14}$ with PKD. Acquired renal cysts may be as a result of chronic renal disease,$^{13}$ administration of chemical substances such as long-acting corticosteroids, ${ }^{9}$ and old age. ${ }^{13}$

Because of the absence of clinical history of renal disease, lack of administration of chemical substances such as long-acting corticosteroids, and correlation with the clinical, radiographic, $\mathrm{CT}$, gross pathology, and histopathologic findings, it is less likely that the polycystic kidneys observed in this case are the result of acquired causes. In human patients, one of the criteria used to distinguish between an acquired and an inherited renal cyst (autosomal dominant PKD) is the presence of extra renal cysts in the liver and pancreas. ${ }^{13}$ In autosomal dominant PKD, extra renal cysts are encountered in the liver and pancreas $^{13}$ as was observed in this case. In acquired renal cysts, extra renal cysts in the liver and pancreas are absent. ${ }^{13}$

The kidney lesions encountered in this case look similar to the kidney lesions found in cats with autosomal dominant PKD. ${ }^{4}$ In cats, the kidneys are grossly characterized by the presence of multiple cysts of variable size in the cortex and medulla. The cysts may contain clear or slightly yellow fluid, blood, fibrin or flocculent material. ${ }^{4}$ On histology, the cysts can originate from any segment of the nephron, they can be empty or contain fibrin, blood, scattered degenerated epithelial cells, and scant proteinaceous material. ${ }^{4} \mathrm{As}$ the cysts enlarge, they lose their connection from the renal tubules. ${ }^{7}$ Mild to severe chronic tubulointerstitial nephritis is frequently observed and is 

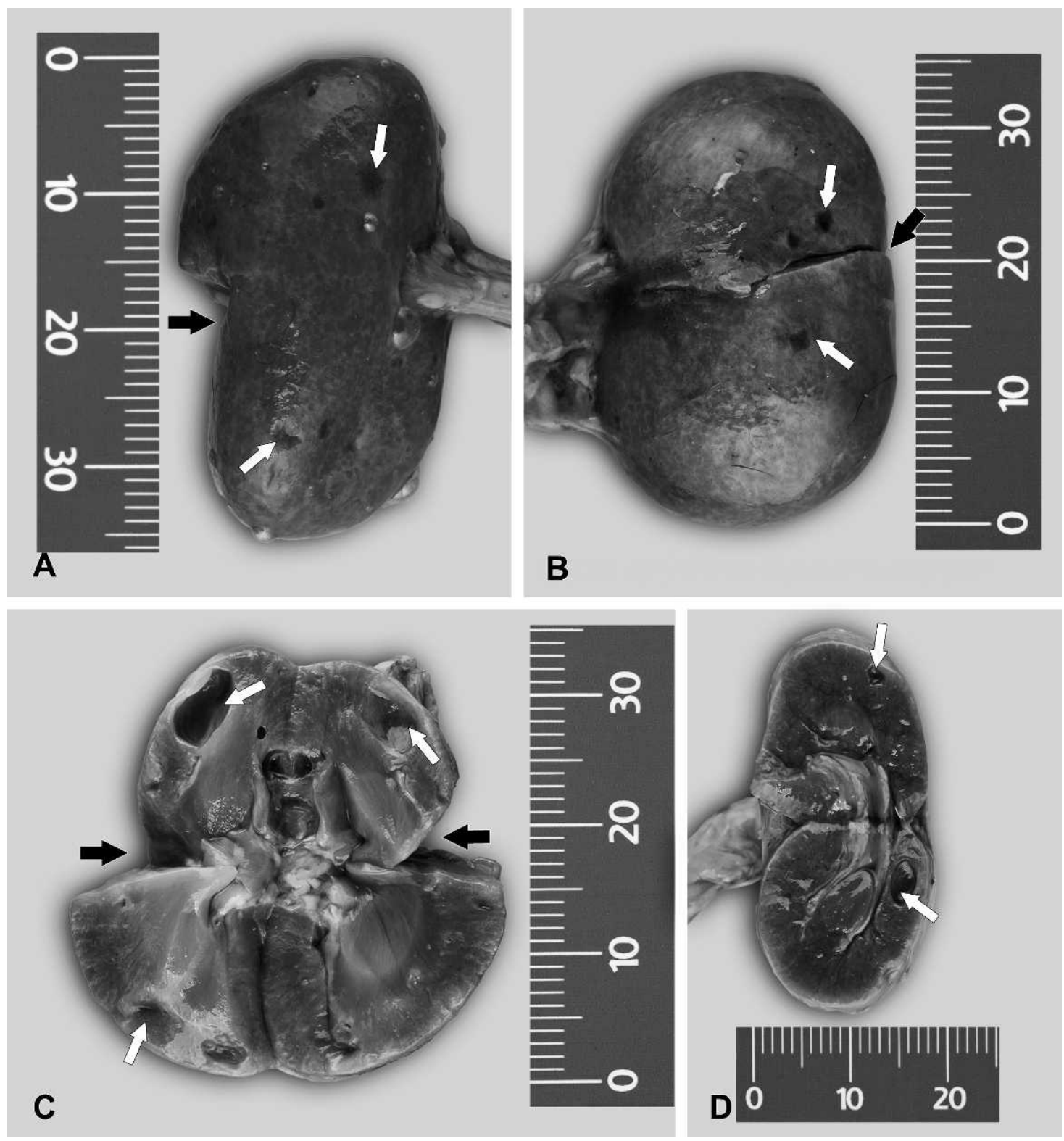

Figure 2. (A and $\mathbf{C})$ Left and (B and $\mathbf{D})$ right kidneys. Note the presence of multiple cysts of various sizes seen from the (A and B) surface, (C) cut sagittal, and (D) transverse views of the kidneys indicated by white arrows. The (A and C) defects (black arrows) and the (B) cut area (black arrow) are the areas where tissue was taken for histopathology examination.

characterized by multifocal to widespread infiltration of plasma cells and lymphocytes, and rare neutrophils. ${ }^{4}$ Furthermore, the lesions are commonly accompanied by interstitial fibrosis and tubular epithelial atrophy and regeneration. ${ }^{4}$

Extrarenal lesions that have been reported in cats with autosomal dominant PKD are hepatobiliary fibrosis and hepatic cysts. ${ }^{4}$ Hepatic cysts were only found in two out of 33 studied cats, ${ }^{4}$ which may explain why they were not observed in this case. In humans, apart from the pancreas, cysts can also be present in the liver, seminal vesicles, and arachnoid membrane, with hepatic cysts being the most common extrarenal manifestation ${ }^{15}$ followed by pancreatic cysts. In humans, pancreatic cysts are small, measuring $\leq 8 \mathrm{~mm}$. The majority of them are seen on microscopic examination and they are always asymptomatic. ${ }^{5}$ This 
might explain why they are not commonly reported in domestic dogs and cats with autosomal dominant PKD. The bile duct hyperplasia was only seen in a single portal tract in this case and is merely speculated if it is at all related to renal and pancreatic cysts.

The differential diagnoses of the focal round hyperattenuating area that was observed in the right cranial liver on CT examination are dystrophic mineralization, cholelith, and mineralized regenerative nodule. Multiple areas of spondylosis observed in this case are incidental findings and age-related. Similar changes are observed in small animals and are milder and less frequently observed in domestic cats. ${ }^{2}$

In humans, renal cysts due to autosomal dominant PKD are more hypoattenuating than normal parenchyma on CT examination, ${ }^{11}$ which is similar to this case. Computed tomography is more sensitive for detection of PKD compared to ultrasonography; however, ultrasonography is commonly used because of its relatively low cost and greater safety. ${ }^{15}$

The cystic lesions in the kidneys encountered in this case are similar to those reported in domestic cats with autosomal dominant PKD. Polycystic kidneys have also been observed in a lion. ${ }^{8}$ The exact cause of the cystic lesions in this case cannot be determined. It would have been helpful in this case to investigate the existence of polycystic kidneys in red pandas related to this case; however, that was not possible. Further studies in this species to determine the potential existence of inherited PKD is warranted.

Acknowledgments: The authors would like to thank Prof. Ann Carstens and radiology sisters of Onderstepoort Veterinary Academic Hospital for their assistance with computed tomography and radiology, and Dr. Georgia for her assistance with anesthesia and postmortem examination. The authors also thank the Organization for Women in Science for the Developing World, Swedish International Development Cooperation Agency, University of Pretoria, and Johannesburg Zoo for their support and Mrs. Charmaine Vermeulen and Mrs. Wilma Olivier of the University of Pretoria for assisting in preparation of figures and administrative work, respectively.

\section{LITERATURE CITED}

1. Biller, D. S., S. P. DiBartola, K. A. Eaton, S. Pflueger, M. L. Wellman, and M. J. Radin. 1996.
Inheritance of polycystic kidney disease in Persian cats. J. Hered. 87: 1-5.

2. Clarke, S. P., D. Mellor, D. N. Clements, T. Gemmill, M. Farrell, S. Carmichael, and D. Bennett. 2005. Prevalence of radiographic signs of degenerative joint disease in a hospital population of cats. Vet. Rec. 157: 793-799.

3. Crowell, W. A., J. J. Hubbell, and J. C. Riley. 1979. Polycystic renal disease in related cats. J. Am. Vet. Med. Assoc. 175: 286-288.

4. Eaton, K. A., D. S. Biller, S. P. DiBartola, M. J. Radin, and M. L. Wellman. 1997. Autosomal dominant polycystic kidney disease in Persian and Persian-cross cats. Vet. Pathol. 34: 117-126.

5. Fick, G. M., A. M. Johnson, W. S. Hammond, and P. A. Gabow. 1995. Causes of death in autosomal dominant polycystic kidney disease. J. Am. Soc. Nephrol. 5: 2048-2056.

6. Fisher, R. E., B. Adrian, M. Barton, J. Holmgren, and S. Y. Tang. 2009. The phylogeny of the red panda (Ailurus fulgens): evidence from the forelimb. J. Anat. 215: 611-635.

7. Gabow, P. A. 1993. Autosomal dominant polycystic kidney disease. N. Engl. J. Med. 329: 332-342.

8. Gerhauser, I., U. Philipp, O. Distl, and A. Beineke. 2009. Multiple cyst formation in the liver and kidneys of a lion (Panthera leo). A case of polycystic kidney disease. Eur. J. Wildl. Res. 55: 433-437.

9. Grant Maxie, M., and S. J. Newman. 2007. Urinary system. In: Maxie, Grant M. (ed.). Jubb, Kennedy and Palmer's Pathology of Domestic Animals. Elsevier Saunders, Philadelphia. Pp. 425-522.

10. Heath, T., and J. Platnick. 2008. "Ailurus fulgens" Animal Diversity Web. http://animaldiversity.ummz. umich.edu/accounts/Ailurus_fulgens/. Accessed 4 April 2013.

11. Lieske, J. C., and F. G. Toback. 1993. Autosomal dominant polycystic kidney disease. J. Am. Soc. Nephrol. 3: 1442-1450.

12. McAloose, D., M. Casal, D. F. Patterson, and D. M. Dambach. 1998. Polycystic kidney and liver disease in two related West Highland white terrier litters. Vet. Pathol. 35: 77-81.

13. Nahm, A.-M., and E. Ritz. 2001. Acquired renal cysts. Nephrol. Dial. Transplant. 16: 1506-1508.

14. O'Leary, C. A., B. M. Mackay, R. Malik, J. E. Edmondston, W. F. Robinson, and C. R. Huxtable. 1999. Polycystic kidney disease in bull terriers: an autosomal dominant inherited disorder. Aust. Vet. J. 77: 361-366.

15. Torres, V., P. C. Harris, and Y. Pirson. 2007. Autosomal dominant polycystic kidney disease. Lancet 369: 1287-301.

16. Zerres, K., S. Rudnik-Schöneborn, C. Steinkamm, J. Becker, and G. Mücher. 1998. Autosomal recessive polycystic kidney disease. J. Mol. Med. 76: 303-309.

Received for publication 2 December 2012 